\title{
A Generalized Plasticity-Based Model for Sandstone Considering Time-Dependent Behavior and Wetting Deterioration
}

\author{
Meng-Chia Weng
}

Received: 22 December 2012/ Accepted: 1 August 2013/Published online: 18 August 2013

(C) The Author(s) 2013. This article is published with open access at Springerlink.com

\begin{abstract}
Based on the concept of generalized plasticity, this study proposes a constitutive model to describe the time-dependent behavior and wetting deterioration of sandstone. The proposed model (1) exhibits nonlinear elasticity under hydrostatic and shear loading, (2) follows the associated flow rule for viscoplastic deformation, (3) adopts a creep modulus that varies with the stress ratio, (4) considers the primary and secondary creep behaviors of rock, and (5) considers the effect of wetting deterioration. This model requires 13 material parameters, comprising 3 for elasticity, 7 for plasticity, and 3 for creep. All parameters can be determined easily by following the suggested procedures. The proposed model is first validated by comparison with triaxial tests of sandstone under different hydrostatic stress and cyclic loading conditions. In addition, the model is versatile in simulating time-dependent behavior through a series of multistage creep tests. Finally, to consider the effects of wetting deterioration, triaxial and creep tests under dry and water-saturated conditions are simulated. Comparison of the simulated and experimental data shows that the proposed model can predict the behavior of sandstone in dry and saturated conditions.
\end{abstract}

Keywords Constitutive model · Creep ·

Generalized plasticity $\cdot$ Sandstone

M.-C. Weng ( $\square)$

Department of Civil and Environmental Engineering, National

University of Kaohsiung, 700, Kaohsiung University Rd,

Kaohsiung 81148, Taiwan, ROC

e-mail: mcweng@nuk.edu.tw

\section{Introduction}

The theory of generalized plasticity was first introduced by Zienkiewicz and Mroz (1984) to simulate soil behavior and was later elaborated by Pastor and Zienkiewicz (1986) and Pastor et al. (1990). In contrast to other plastic models, this theory does not explicitly define the yield and plastic potential surfaces. Instead, it adopts the gradients of these functions so that simple models within this framework can consider material behavior responses under loading. Generalized plasticity considers plastic deformation at any stress level for stress increments in both loading and unloading conditions. These features enable the generalized plasticity model to predict the stress-strain behavior of numerous soil types with good accuracy under various types of loading. Researchers have recently developed various constitutive relationships based on this framework to describe sophisticated features encompassing soil behavior, including anisotropy (Pastor 1991; Pastor et al. 1992), unsaturated conditions (Bolzon et al. 1996; Manzanal et al. 2011b), degradation phenomena (Fernandez Merodo et al. 2004), and the effects of stress levels and densification on sand (Ling and Liu 2003; Ling and Yang 2006; Manzanal et al. 2006, 2011a). Notably, the transformation of this theory from the defining space to general Cartesian stress space is one of the key steps in extending it to computational implementations (Chan et al. 1988).

Other than soil, Weng and Ling (2012) adopted the generalized plasticity concept to investigate nonlinear elasticity behavior in rock. The proposed model produces reasonable predictions of the elastoplastic deformation of sandstone under varying stress paths, cyclic loadings, and postpeak behavior. In addition to simulating immediate rock deformation, the time-dependent deformation (i.e., creep deformation) of rock is a major concern in engineering practice 
(Cristescu 1989; Hoxha et al. 2005; Tomanovic 2006; Xie and Shao 2006; Sterpi and Gioda 2009; Weng et al. 2010a, b). According to previous studies on creep deformation of sandstone (Tsai et al. 2008; Weng et al. 2010a), viscoplastic flows indicate that the viscoplastic potential surface has a similar shape to the plastic potential surface, but the size of the viscoplastic potential surface changes with time. The plastic potential surface has a time-independent size. Meanwhile, through calculation of the irreversible work, direct evidence of orthogonality between the yield surface and the plastic flow, as well as the viscoplastic flow, has been observed. Thus, it is reasonable to state that the yield surface, plastic potential, and viscoplastic potential all have the same geometry. Consequently, the associated flow rules are applicable for modeling the time-dependent deformational behavior of sandstone.

Based on these characteristics of sandstone, this study extends the work of Weng and Ling (2012) to develop an elastic-viscoplastic model that incorporates the generalized plasticity concept. This study also presents an assessment of the validity of the proposed model by comparing simulated and actual deformations in various multistage creep tests. Moreover, the strength and stiffness of sandstone are significantly reduced because of the wetting process (Dyke and Dobereiner 1991; Hawkins and McConnell 1992; Jeng et al. 2004). This phenomenon commonly occurs in sandstone of medium to moderate strength. To evaluate the performance of the proposed model for the wetting deterioration of sandstone, this study employs the proposed model to simulate triaxial and creep tests of deformational behaviors under dry and water-saturated conditions.

\section{Model Concept}

Based on the concept of generalized plasticity, the total strain increment can be divided into elastic and plastic components as follows:

$\mathrm{d} \varepsilon=\mathrm{d} \varepsilon^{\mathrm{e}}+\mathrm{d} \varepsilon^{\mathrm{p}}$

where $\mathrm{d} \varepsilon, \mathrm{d} \varepsilon^{\mathrm{e}}$, and $\mathrm{d} \varepsilon^{\mathrm{p}}$ are the increments of the total, elastic, and plastic strain tensors, respectively.

The elastic and plastic strain increments can be obtained from

$\mathrm{d} \varepsilon^{\mathrm{e}}=\boldsymbol{C}^{\mathrm{e}}: \mathrm{d} \sigma$

and

$\mathrm{d} \varepsilon^{\mathrm{p}}=\mathrm{d} \lambda \boldsymbol{n}_{\mathrm{g}}=\frac{1}{H_{\mathrm{L} / \mathrm{U}}}\left(\boldsymbol{n}_{\mathrm{gL} / \mathrm{U}} \otimes \boldsymbol{n}\right): \mathrm{d} \sigma$,

where $C^{\mathrm{e}}$ is the elastic constitutive tensor, $\mathrm{d} \sigma$ is the increment of the stress tensor, $\boldsymbol{n}_{\mathrm{g}}$ is the unit vector defining the plastic flow direction, $\boldsymbol{n}$ represents the loading-direction vector, $\mathrm{d} \lambda$ is a plastic scalar, and $H_{\mathrm{L} / \mathrm{U}}$ is the plastic modulus, which can be assumed directly without introducing a hardening rule. Subscripts " $L$ " and " $U$ " indicate loading and unloading, respectively.

To consider time-dependent deformation, the plastic strain increment $\mathrm{d} \varepsilon^{\mathrm{p}}$ can be substituted by the viscoplastic strain increment $\mathrm{d} \varepsilon^{\mathrm{vp}}$. Equation (3) can then be modified to

$\mathrm{d} \varepsilon^{\mathrm{vp}}=\frac{1}{H_{\mathrm{L} / \mathrm{U}}}\left(\boldsymbol{n}_{\mathrm{gL} / \mathrm{U}} \otimes \boldsymbol{n}\right): \mathrm{d} \sigma+\frac{G(t)}{H_{\mathrm{c}}}\left(\boldsymbol{n}_{\mathrm{c}} \otimes \boldsymbol{n}\right): \mathrm{d} \sigma$,

where $H_{\mathrm{c}}$ is the creep modulus, $G(t)$ is a time-dependent function, and $\boldsymbol{n}_{\mathrm{c}}$ is the viscoplastic flow vector. The concept employed in Eq. 4 is similar to the viscoelastic model in rheology. The first term $\frac{1}{H_{\mathrm{L} / \mathrm{U}}}\left(\boldsymbol{n}_{\mathrm{gL} / \mathrm{U}} \otimes \boldsymbol{n}\right): \mathrm{d} \sigma$ represents instantaneous deformation, whereas the second term $\frac{G(t)}{H_{\mathrm{c}}}\left(\boldsymbol{n}_{\mathrm{c}} \otimes \boldsymbol{n}\right): \mathrm{d} \sigma$ corresponds to long-term deformation, including the primary and secondary creep behavior of the rock.

Based on this concept of generalized plasticity, the yield and viscoplastic potential surfaces are not directly specified, but the scalar functions for plastic modulus $H_{\mathrm{L} / \mathrm{U}}$, creep modulus $H_{\mathrm{c}}$, and direction tensors $\boldsymbol{n}, \boldsymbol{n}_{\mathrm{g}}$, and $\boldsymbol{n}_{\mathrm{c}}$ are required. To incorporate the deformation characteristics of sandstone into the generalized plasticity, this study proposes (and subsequently defines) the major constituents of the model, including nonlinear elasticity, dilatancy, plastic modulus, and a time-dependent function.

\subsection{Nonlinear Elastic Behavior}

According to hyperelasticity theory, the strain tensor is related to the derivatives of the energy density function as follows:

$\varepsilon^{\mathrm{e}}=\frac{\partial \Omega}{\partial \sigma}$

where $\Omega$ is the energy density function. Based on experimental sandstone results, this study adopts the following energy density function for $\Omega$, which has been proposed by previous studies (Weng et al. 2010a; Weng and Ling 2012):

$\Omega=b_{1} I_{1}^{3 / 2}+b_{2} I_{1}^{-1} J_{2}+b_{3} J_{2}$,

where $b_{1}, b_{2}$, and $b_{3}$ are material parameters, $I_{1}$ is the first stress invariant $\left(I_{1}=\sigma_{k k}=3 p^{\prime}\right)$, and $J_{2}$ is the second deviatoric stress invariant $\left(J_{2}=\frac{1}{2} s_{i j} s_{j i}\right.$, where $s_{i j}$ is the deviatoric stress tensor). After substituting Eq. (6) into Eq. (5), the elastic strain tensor $\varepsilon_{i j}^{\mathrm{e}}$ takes the following form:

$$
\begin{aligned}
\varepsilon_{i j}^{\mathrm{e}} & =\frac{\partial \Omega}{\partial \sigma_{i j}} \\
& =\left(3 / 2 b_{1} I_{1}^{1 / 2}-b_{2} I_{1}^{-2} J_{2}+J_{2}\right) \delta_{i j}+\left(b_{2} I_{1}^{-1}+b_{3}\right) s_{i j}
\end{aligned}
$$


where $\delta_{i j}$ is the Kronecker delta tensor.

Equation (7) shows that the increment of the elastic strain tensor $\mathrm{d} \varepsilon_{i j}^{\mathrm{e}}$ is

$$
\begin{aligned}
\mathrm{d} \varepsilon_{i j}^{\mathrm{e}}= & \frac{\partial^{2} \Omega}{\partial \sigma_{i j} \partial \sigma_{k l}} \mathrm{~d} \sigma_{k l}=C_{i j k l}^{\mathrm{e}} \mathrm{d} \sigma_{k l}, \\
\mathrm{~d} \varepsilon_{i j}^{\mathrm{e}}= & {\left[\Phi_{1} \delta_{i j} \delta_{k l}+\Phi_{2} \delta_{i j} s_{k l}+\Phi_{3} \delta_{i k} \delta_{j l}\right.} \\
& \left.-\frac{1}{3} \Phi_{3} \delta_{i j} \delta_{k l}+\Phi_{2} \delta_{k l} s_{i j}\right] \mathrm{d} \sigma_{k l},
\end{aligned}
$$

where $\Phi_{1}=3 / 4 b_{1} I_{1}^{-1 / 2}+2 b_{2} I_{1}^{-3} J_{2}, \Phi_{2}=-b_{2} I_{1}^{-2}, \quad$ and $\Phi_{3}=b_{2} I_{1}^{-1}+b_{3}$. Equations (7) and (8) are derived from rigorous elastic theory, and satisfy the principle of thermodynamics, which indicates that energy is conserved during any type of loading. A similar relationship based on hyperelasticity was also proposed by Houlsby et al. (2005); they adopted a power function of the stress to describe the nonlinear elastic stiffness of soil. Mira et al. (2009) combined the work of Houlsby et al. (2005) and generalized plasticity to successfully predict soil behavior under cyclic loading.

Based on Eq. (7), the elastic strain induced in the shearloading stage can be calculated as shown in Eqs. (9) and (10):

$\varepsilon_{\mathrm{v}}^{\mathrm{e}}=-3 b_{2}\left(\sqrt{J_{2}} / I_{1}\right)^{2}$

$\gamma^{\mathrm{e}}=\frac{2}{\sqrt{3}}\left(b_{2} I_{1}^{-1}+b_{3}\right) \sqrt{J_{2}}$.

Equations (9) and (10) show two features of the proposed model: (1) shear loading induces elastic dilative deformation, and (2) the elastic shear stiffness increases with the application of increasing hydrostatic pressure. In addition, greater values for the parameters $b_{1}, b_{2}$, and $b_{3}$ indicate that increasing elastic strain is generated by the model.

\subsection{Dilatancy and Viscoplastic Flow}

For stress-dilatancy relationships, this study adopts a function similar to that of Pastor et al. (1990), relating the dilatancy $d_{\mathrm{g}}$ and stress ratio $\eta$ as follows:

$d_{\mathrm{g}}=\frac{\mathrm{d} \varepsilon_{\mathrm{v}}^{\mathrm{p}}}{\mathrm{d} \gamma^{\mathrm{p}}}=(1+\alpha)\left(M_{\mathrm{g}}-\eta\right)$

where $\mathrm{d} \varepsilon_{\mathrm{v}}^{\mathrm{p}}$ and $\mathrm{d} \gamma^{\mathrm{p}}$ are the incremental plastic volumetric and shear strain, respectively. The term $M_{\mathrm{g}}$ is the threshold of shear dilation in the triaxial plane. When $\eta=M_{\mathrm{g}}, d_{\mathrm{g}}$ equals zero and volumetric strain does not occur. The sandstone converts from compression to dilation when $\eta>M_{\mathrm{g}} \cdot \alpha$ is a model parameter.

Based on the definition by Weng and Ling (2012), the stress ratio $\eta$ here is defined as $\eta=q / q_{\mathrm{f}}$

where $q=\sqrt{3 J_{2}}$ and $q_{\mathrm{f}}$ is the shear strength. The linear strength criterion, known as the Drucker-Prager criterion, is adopted as follows:

$q_{\mathrm{f}}=\sqrt{3 J_{2 \mathrm{f}}}=\sqrt{3}\left(\alpha_{\mathrm{d}} I_{1}+k_{\mathrm{d}}\right)$,

where the parameters $\alpha_{\mathrm{d}}$ and $k_{\mathrm{d}}$ are the slope and cohesive intercept of the failure envelope, respectively. If the shear strength exhibits a nonlinear failure envelope, use of the Hoek-Brown criterion (Hoek and Brown 1980) for rock is recommended.

To further investigate the variation of dilatancy with the stress ratio, the actual behavior of sandstone was compared with the proposed model. The plastic flow angle $\beta_{1}$ is defined by

$\tan \beta_{1}=\frac{\mathrm{d} \gamma^{\mathrm{p}}}{\mathrm{d} \varepsilon_{\mathrm{V}}^{\mathrm{p}}}=\frac{1}{d_{\mathrm{g}}}$.

When $\beta_{1}$ ranges from $0^{\circ}$ to $90^{\circ}, \mathrm{d} \varepsilon_{\mathrm{v}}^{\mathrm{p}}$ indicates compression. Conversely, when $\beta_{1}$ is $>90^{\circ}, \mathrm{d} \varepsilon_{\mathrm{v}}^{\mathrm{p}}$ is dilative. Figure 1 shows the typical variation of the plastic angle $\beta_{1}$ with the stress ratio. At low stress ratio, the plastic angle $\beta_{1}$ is smaller than $90^{\circ}$, and gradually increases with the shear stress ratio. When the stress ratio $\eta$ equals $M_{\mathrm{g}}, \beta_{1}$ becomes $90^{\circ}$ and the volumetric deformation begins to dilate. In addition to $M_{\mathrm{g}}$, the parameter $\alpha$ affects the slope of the proposed model; as $\alpha$ increases, $\beta_{1}$ becomes flatter.

Furthermore, the viscoplastic flow angle $\beta_{2}$ is defined as

$\tan \beta_{2}=\frac{d \gamma_{t_{0} \rightarrow t}^{v p}}{d \varepsilon_{v\left(t_{0} \rightarrow t\right)}^{v p}}$

where $\mathrm{d} \gamma_{t_{0} \rightarrow t}^{\mathrm{vp}}$ is the creep shear-strain increment from time $t_{0}$ to $t, \mathrm{~d} \varepsilon_{v\left(t_{0} \rightarrow t\right)}^{\mathrm{vp}}$ is the creep volumetric-strain increment from time $t_{0}$ to $t$, and $t_{0}$ is the initiation time of one particular loading step in a sequence of loading steps

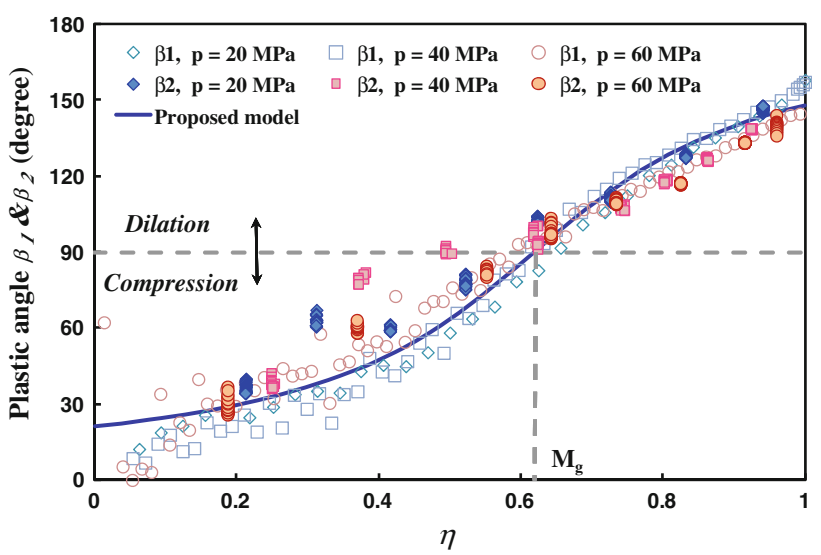

Fig. 1 Variations of the plastic flow angle $\beta_{1}$ and viscoplastic flow angle $\beta_{2}$ under shear loading with different confining pressures. $\eta$ is defined as $q / q_{\mathrm{f}}$ and serves as an index of the degree of shear loading. Dilation occurs when $\beta$ is $>90^{\circ}$ 
during testing under either increasing or constant loading (creep test condition). The time $t$ is an arbitrary time after creep begins. Figure 1 shows the variation in the viscoplastic flow angle $\beta_{2}$ with the stress ratio $\eta$. The tendency of the viscoplastic flow angle $\beta_{2}$ is relatively consistent with that of the plastic flow angle $\beta_{1}$ (Fig. 1), indicating that the viscoplastic flow vector is likely the same as the plastic flow (i.e., $\boldsymbol{n}_{\mathrm{c}}=\boldsymbol{n}_{\mathrm{g}}$ ). In addition, the proposed model reasonably simulates these two variations. Based on this assumption, Eq. (4) can be modified to

$\mathrm{d} \varepsilon^{\mathrm{vp}}=\frac{1}{H_{\mathrm{L} / \mathrm{U}}}\left(\boldsymbol{n}_{\mathrm{gL} / \mathrm{U}} \otimes \boldsymbol{n}\right): \mathrm{d} \sigma+\frac{G(t)}{H_{\mathrm{c}}}\left(\boldsymbol{n}_{\mathrm{gL} / \mathrm{U}} \otimes \boldsymbol{n}\right):$

$\mathrm{d} \sigma=\frac{1}{H_{\mathrm{L} / \mathrm{U}}}\left(1+\frac{H_{\mathrm{L} / \mathrm{U}}}{H_{\mathrm{c}}} G(t)\right)\left(\boldsymbol{n}_{\mathrm{gL} / \mathrm{U}} \otimes \boldsymbol{n}\right):$

$\mathrm{d} \sigma=\frac{1}{H_{\mathrm{vp}}}\left(\boldsymbol{n}_{\mathrm{gL} / \mathrm{U}} \otimes \boldsymbol{n}\right): \mathrm{d} \sigma$,

where $H_{\mathrm{vp}}$ is the viscoplastic modulus. To express the stress increments as a function of strain increments, Eq. (16) is inverted and expressed as

$\mathrm{d} \sigma=\boldsymbol{D}^{\mathrm{evp}}: \mathrm{d} \varepsilon$

$\boldsymbol{D}^{\mathrm{evp}}=\boldsymbol{D}^{\mathrm{e}}-\frac{\boldsymbol{D}^{\mathrm{e}}: \boldsymbol{n}_{\mathrm{gL} / \mathrm{U}} \otimes \boldsymbol{n}: \boldsymbol{D}^{\mathrm{e}}}{H_{\mathrm{vp}}+\boldsymbol{n}: \boldsymbol{D}^{\mathrm{e}}: \boldsymbol{n}_{\mathrm{gL} / \mathrm{U}}}$,

where $\boldsymbol{D}^{\text {evp }}$ and $\boldsymbol{D}^{\mathrm{e}}$ are the elasto-viscoplastic and elastic tensors, respectively.

According to Pastor et al. (1990), the viscoplastic flow direction under loading and unloading $\boldsymbol{n}_{\mathrm{gL} / \mathrm{U}}$ in triaxial space is

$\boldsymbol{n}_{\mathrm{gL} / \mathrm{U}}=\left(\frac{d_{\mathrm{g}}}{\sqrt{1+d_{\mathrm{g}}^{2}}}, \frac{1}{\sqrt{1+d_{\mathrm{g}}^{2}}}\right)^{\mathrm{T}}$.

Similarly, the loading-direction vector can be expressed as

$\boldsymbol{n}=\left(\frac{d_{\mathrm{f}}}{\sqrt{1+d_{\mathrm{f}}^{2}}}, \frac{1}{\sqrt{1+d_{\mathrm{f}}^{2}}}\right)^{\mathrm{T}}$,

where $d_{\mathrm{f}}=((1+\alpha))\left(M_{\mathrm{f}}-\eta\right)$ and $M_{\mathrm{f}}$ is a material parameter.

According to Jeng et al. (2002), Weng et al. (2005), and Tsai et al. (2008), triaxial results show that the plastic potential surface of sandstone coincides with the yield surface in the prepeak stage. Therefore, the associated flow rule, $\boldsymbol{n}=\boldsymbol{n}_{\mathrm{gL} / \mathrm{U}}$ and $M_{\mathrm{f}}=M_{\mathrm{g}}$, can be used when formulating the constitutive model for sandstone. However, $\boldsymbol{n}$ should be specified differently from $\boldsymbol{n}_{\mathrm{gL} / \mathrm{U}}$, and the nonassociated flow rule should be followed if the softening (postpeak) behavior is considered (Weng and Ling 2012).

\subsection{Plastic Modulus for Loading and Unloading}

Figure 2 shows the variation of the plastic modulus of sandstone at various stages of shear loading. This figure indicates that the plastic modulus decreases as the stress ratio rises. In particular, the modulus decreases by approximately three orders of magnitude when approaching the failure state $(\eta=0.8-1)$. Based on this tendency, the function of the plastic modulus for sandstone under loading can be expressed as

$H_{\mathrm{L}}=H_{0} \sqrt{p^{\prime} / p_{\text {atm }}} H_{\mathrm{f}} H_{\mathrm{s}}$,

$H_{\mathrm{f}}=\left(1-\eta^{2}\right)$,

$H_{\mathrm{s}}=\exp \left(-\beta_{0} \xi_{\mathrm{s}}\right)$,

where $H_{0}$ is a multiplication factor related to the initial plastic modulus, $H_{\mathrm{f}}$ and $H_{\mathrm{s}}$ are plastic coefficients, $p_{\mathrm{atm}}$ is the atmospheric pressure, $\beta_{0}$ is a material parameter, and $\xi_{\mathrm{s}}=\int\left|\mathrm{d} \gamma \gamma^{\mathrm{p}}\right|=\int \mathrm{d} \xi_{\mathrm{s}}$ is the accumulated plastic shear strain.

The original model suggests that plastic strain also occurs during the unloading process; the unloading plastic modulus $H_{\mathrm{U}}$ can be expressed as

$H_{\mathrm{U}}=H_{\mathrm{U} 0}$,

where $H_{\mathrm{U} 0}$ is a material parameter.

\subsection{Creep Modulus for Time-Dependent Behavior}

For time-dependent deformation, Fig. 3 shows the variation of the creep modulus of sandstone for various stress ratios. This figure shows variations similar to that of the plastic modulus (Fig. 2). Thus, the function of the creep modulus for sandstone can be written as

$H_{\mathrm{c}}=H_{\mathrm{c} 0} \sqrt{p^{\prime} / p_{\mathrm{atm}}} H_{\mathrm{f}}^{\prime} H_{\mathrm{s}}$,

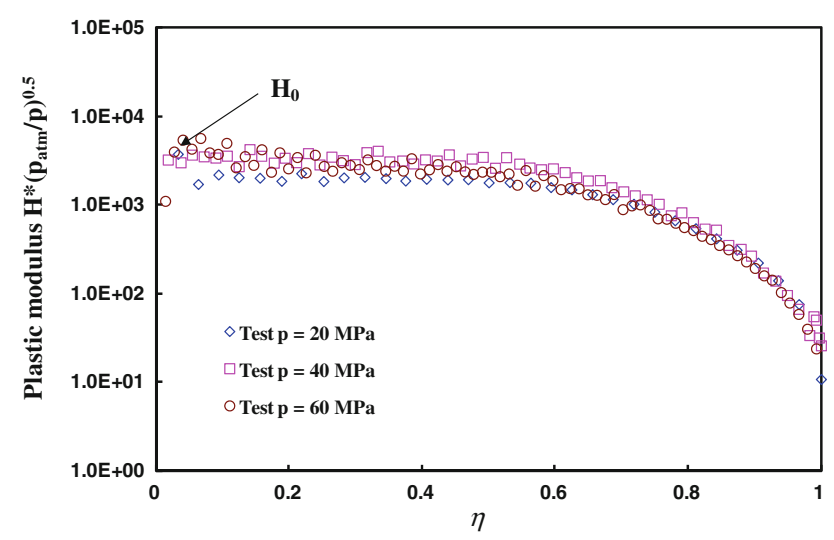

Fig. 2 Variation of the normalized plastic modulus $H_{\mathrm{L}} \sqrt{p_{\text {atm }} / p^{\prime}}$ under shear loading with different confining pressures 
$H_{\mathrm{f}}^{\prime}=(1-\eta)^{2}$,

where $H_{\mathrm{c} 0}$ is a factor related to the initial creep modulus. Considering the primary and secondary creep behaviors of rock (Goodman 1989), this study proposes the following time-dependent function:

$G(t)=1-\exp \left[c_{1}\left(t-t_{0}\right)\right]+c_{2} \eta\left(t-t_{0}\right)$,

where $c_{1}$ and $c_{2}$ are material parameters. The term $1-$ $\exp \left[-c_{1}\left(t-t_{0}\right)\right]$ is adopted to describe the primary creep behavior, while the term $c_{2} \eta\left(t-t_{0}\right)$ corresponds to secondary creep deformation. As $\eta$ increases, the secondary creep deformation develops more rapidly.

\section{Parameter Determination}

There are a total of 13 material parameters $\left(b_{1}, b_{2}, b_{3}, \alpha_{\mathrm{d}}, k_{\mathrm{d}}, M_{\mathrm{g}}, \alpha, H_{0}, \beta_{0}, H_{\mathrm{U} 0}, H_{\mathrm{c} 0}, c_{1}, c_{2}\right)$ to be determined from experimental results. The influence of these parameters on the deformation behavior is relatively straightforward. The parameters $b_{1}, b_{2}$, and $b_{3}$ are elastic parameters; $\alpha_{\mathrm{d}}$ and $k_{\mathrm{d}}$ are strength parameters; $M_{\mathrm{g}}$ and $\alpha$ are parameters related to the stress-dilatancy relationship; $H_{0}$ and $\beta_{0}$ are parameters representing the variation of the loading plastic modulus; $H_{\mathrm{U} 0}$ is a parameter related to the unloading plastic modulus; and $H_{\mathrm{c} 0}, c_{1}$, and $c_{2}$ are timedependent parameters. To obtain the values of these parameters, it is recommended to conduct three triaxial tests with various hydrostatic pressures and one multistage creep test. The difference between the hydrostatic pressures should be sufficiently great to encompass the range of stress levels of interest. Furthermore, the test with the medium hydrostatic pressure should be conducted with multiple unloading-reloading procedures to distinguish and separate elastic deformation from total deformation. The creep test should involve at least three shear-loading stages.

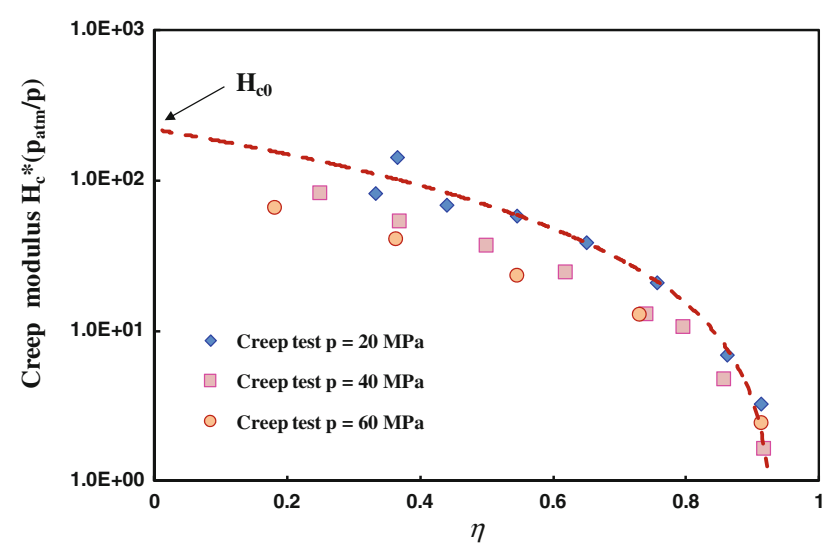

Fig. 3 Variation of the normalized creep modulus $H_{\mathrm{c}}\left(p_{\mathrm{atm}} / p^{\prime}\right)$ under shear loading with different confining pressures
The following section demonstrates how these parameters can be determined from laboratory experiments using a sample of Mushan sandstone (MS), a weak rock commonly found in mountainous areas of northern Taiwan. The porosity of the sampled specimen, denoted as MS-A, is $\sim 14.1 \%$, and the dry density is $\sim 2.28 \mathrm{~g} / \mathrm{cm}^{3}$. The average uniaxial compressive strength is $37.1 \mathrm{MPa}$ in dry conditions and $28.9 \mathrm{MPa}$ in saturated conditions. Petrographic analysis shows that the percentages of grains, matrices, and voids are 59.9, 26.0, and $14.1 \%$, respectively. The average grain diameter is $\sim 0.24 \mathrm{~mm}$. Mineralogically, MS-A sandstone consists of $90.7 \%$ quartz and $9.0 \%$ rock fragments, and is classified as lithic greywacke (Weng et al. 2008). The following subsections describe the determination of each parameter.

1. Elastic Parameters $b_{1}, b_{2}$, and $b_{3}$

The parameter $b_{1}$ controls the interaction between hydrostatic stress and elastic volumetric strain. This parameter can be determined by fitting the elastic volumetric unloading-reloading regression curve. The parameter $b_{2}$ is related to the coupling between shear

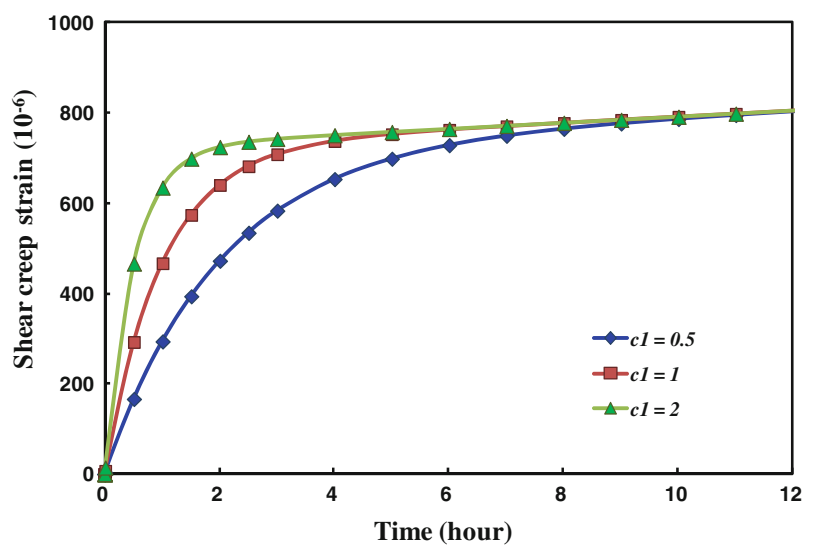

(a) Influence of $c_{1}$

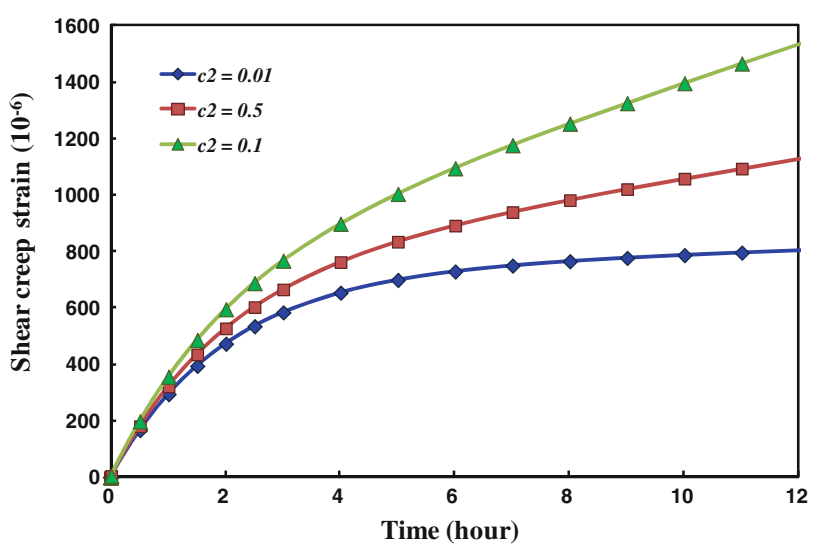

(b) Influence of $c_{2}$

Fig. 4 Influence of the material parameters $c_{1}$ and $c_{2}$ on the simulated creep deformation based on the proposed model 
stress and elastic dilation, and can be obtained by fitting the unloading-reloading regression curve with normalized stress $\left(\sqrt{J_{2}} / I_{1}\right)$ using Eq. (9). After obtaining the parameter $b_{2}$, the parameter $b_{3}$ can be obtained by fitting the shear stress and elastic shear strain curve using Eq. (10).

\section{Strength Parameters $\alpha_{\mathrm{d}}$ and $k_{\mathrm{d}}$}

The parameters $\alpha_{\mathrm{d}}$ and $k_{\mathrm{d}}$ can be determined by fitting the failure envelope of sandstone using Eq. (13).

\section{Stress-Dilatancy Parameters $M_{\mathrm{g}}$ and $\alpha$}

The term $M_{\mathrm{g}}$ is determined by the threshold of shear dilation in a diagram of plastic flow angle $\beta$ versus stress ratio (Fig. 1). Alternatively, this parameter can be obtained directly from the plastic volumetric strain curve under shear loading. The parameter $\alpha$ is determined by fitting the curve of plastic flow angle $\beta$ versus stress ratio (Fig. 1). Another method for obtaining $\alpha$ is from the slope of the graph between dilatancy $d_{\mathrm{g}}$ and $\left(M_{\mathrm{g}} / \eta\right)$.

4. Loading Plastic Modulus Parameters $H_{0}$ and $\beta_{0}$

The initial plastic modulus parameter $H_{0}$ can be determined based on the initial stress ratio in a diagram of the normalized plastic modulus $H_{\mathrm{L}} \sqrt{p_{\text {atm }} / p^{\prime}}$ versus the stress ratio (Fig. 2) or by fitting the initial slope of both the plastic shear and volumetric strain curves under shear loading. In this study, the plastic strain is the unrecoverable deformation under short-term loading (a few minutes). The parameter $\beta_{0}$ controls the degree of plastic modulus degradation; a higher $\beta_{0}$ value induces further significant modulus degradation. This parameter can be determined by matching the shear or volumetric strain curve as the stress ratio $\eta$ approaches 1 .
5. Unloading Plastic Modulus Parameter $H_{\mathrm{U} 0}$

The parameter $H_{\mathrm{U} 0}$ can be determined by matching the slope of the unloading curves.

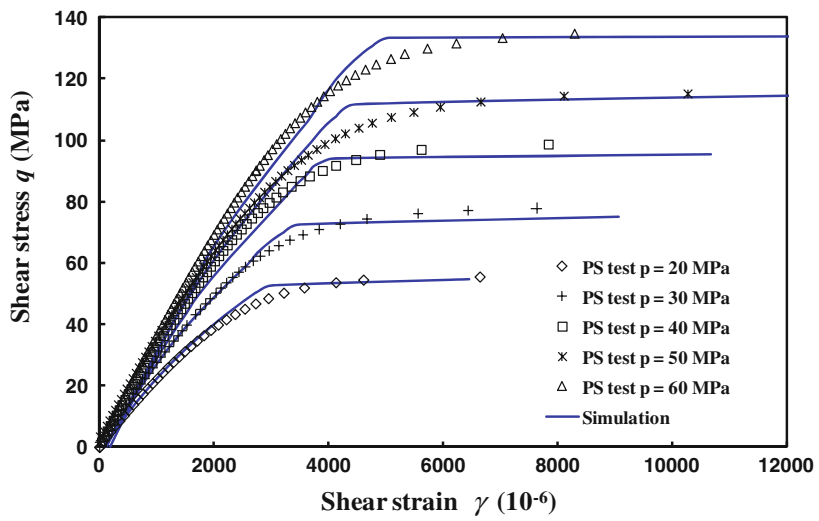

(a) Shear strain

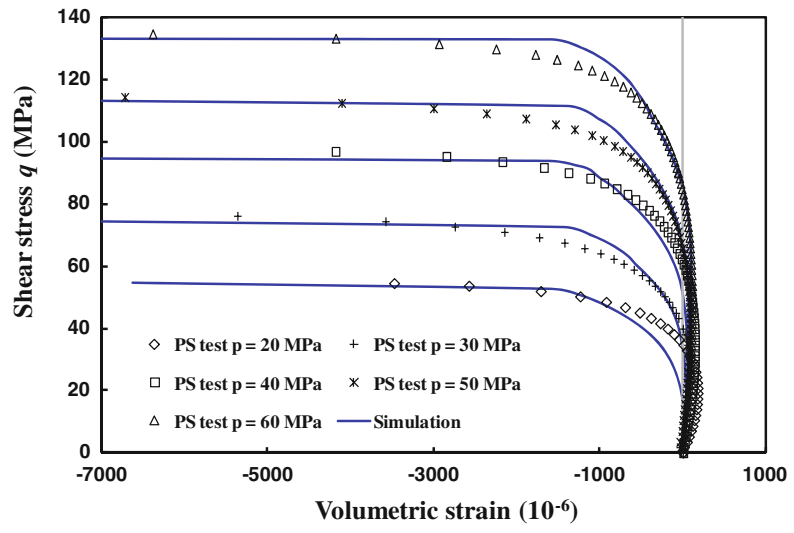

(b) Volumetric strain

Fig. 5 Simulation of stress-strain relationships on dry MS-A sandstone under different hydrostatic pressures

Table 1 Material parameters for different types of sandstone used in the proposed model

\begin{tabular}{|c|c|c|c|c|}
\hline Model property & Parameter & MS-A sandstone & MS-B sandstone (dry) & MS-B sandstone (saturated) \\
\hline \multirow[t]{3}{*}{ Elastic component } & $b_{1}(\mathrm{MPa})^{-1 / 2}$ & $130 \times 10^{-6}$ & $173 \times 10^{-6}$ & $215 \times 10^{-6}$ \\
\hline & $b_{2}$ & $1,463 \times 10^{-6}$ & $2,200 \times 10^{-6}$ & $3,300 \times 10^{-6}$ \\
\hline & $b_{3}(\mathrm{MPa})^{-1 / 2}$ & $29 \times 10^{-6}$ & $35 \times 10^{-6}$ & $50 \times 10^{-6}$ \\
\hline \multirow[t]{2}{*}{ Failure criterion } & $\alpha_{\mathrm{d}}$ & 0.39 & 0.35 & 0.32 \\
\hline & $k_{\mathrm{d}}(\mathrm{MPa})$ & 8.2 & 9.71 & 9.06 \\
\hline \multirow[t]{5}{*}{ Plastic component } & $M_{\mathrm{g}}$ & 0.62 & 0.61 & 0.65 \\
\hline & $\alpha$ & 2.9 & 2.0 & 4.0 \\
\hline & $H_{0}(\mathrm{MPa})$ & 4,590 & 3,067 & 2,530 \\
\hline & $\beta_{0}$ & 120 & 400 & 410 \\
\hline & $H_{\mathrm{U} 0}(\mathrm{MPa})$ & 180,000 & & \\
\hline \multirow[t]{3}{*}{ Time-dependent component } & $H_{\mathrm{c}}(\mathrm{MPa})$ & 540 & 750 & 125 \\
\hline & $c_{1}(\mathrm{~h})^{-1}$ & 0.97 & 2.5 & 2.5 \\
\hline & $c_{2}(\mathrm{~h})^{-1 / 2}$ & 0.012 & 0.02 & 0.018 \\
\hline
\end{tabular}


6. Time-Dependent Parameters $H_{\mathrm{c} 0}, c_{1}$, and $c_{2}$

The initial creep modulus parameter $H_{\mathrm{c} 0}$ can be determined at the initial stress ratio in a diagram of the normalized creep modulus $H_{\mathrm{c}} \sqrt{p_{\text {atm }} / p^{\prime}}$ versus the stress ratio (Fig. 3). The parameter $c_{1}$ controls the retardation time during the primary creep behavior; as $c_{1}$ increases, the primary creep deformation develops more rapidly. Moreover, the parameter $c_{2}$ influences the secondary creep behavior; as $c_{2}$ becomes greater, the secondary creep deformation increases more rapidly. The influence of $c_{1}$ and $c_{2}$ on the creep strain is shown in Fig. 4. The parameter $c_{1}$ can be determined by matching the initial slope of the creep strain versus time curve, and the parameter $c_{2}$ can be determined by matching the final slope of the creep strain versus time curve.

Using these procedures, the corresponding material parameters of MS-A sandstone in dry conditions can be obtained from one triaxial test with a pure shear stress path (PS test) and one creep test, both under hydrostatic pressure of $40 \mathrm{MPa}$. Table 1 presents a summary of these parameter values.

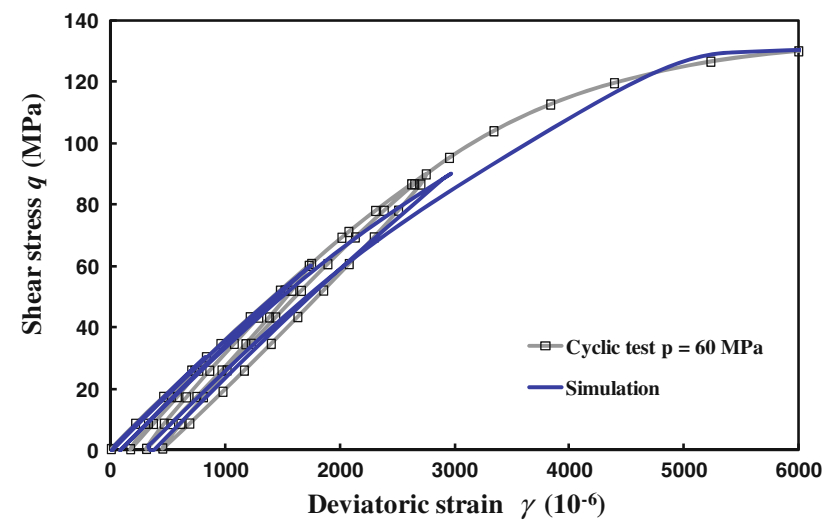

(a) Shear strain

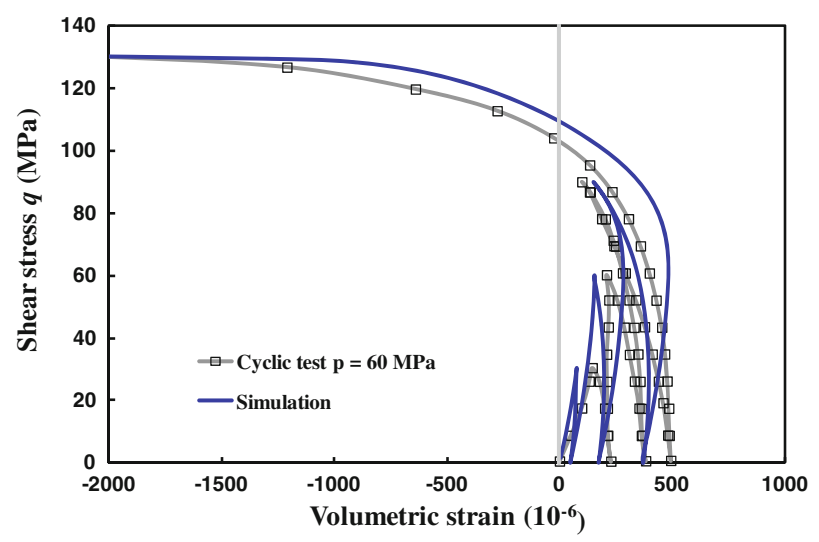

(b) Volumetric strain

Fig. 6 Simulation of loading-unloading-reloading behavior under hydrostatic stress of $60 \mathrm{MPa}$

\section{Model Validation on Immediate Deformation}

To assess the validity of the proposed model, this section shows how the proposed model can simulate the immediate deformation behavior under various hydrostatic stress and cyclic loadings.

Five PS tests of MS-A sandstone with hydrostatic stress ranging from 20 to $60 \mathrm{MPa}$ were simulated. Figure 5a shows the measured and simulated shear-induced shear strains under various hydrostatic stress conditions, exhibiting satisfactory agreement. Figure $5 \mathrm{~b}$ shows the measured and simulated shear-induced volumetric strains under varying hydrostatic stress conditions. These simulated results are consistent with the measured results.

This study also used the proposed model to simulate three stress-controlled unloading-reloading cycles in a PS test. Figure 6 shows a comparison of the simulated and experimental results under constant hydrostatic stress of $60 \mathrm{MPa}$. Although the unloading-reloading-induced deformations are not large in either the shear or volumetric

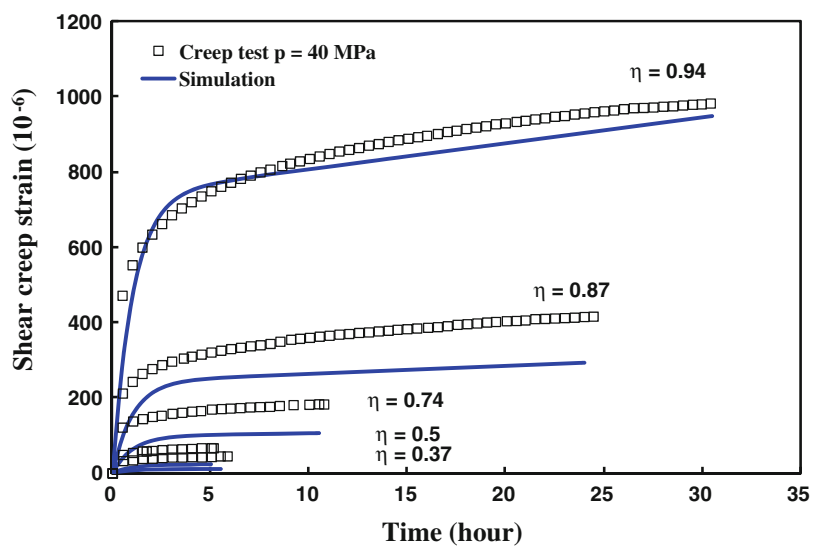

(a) Shear creep strain

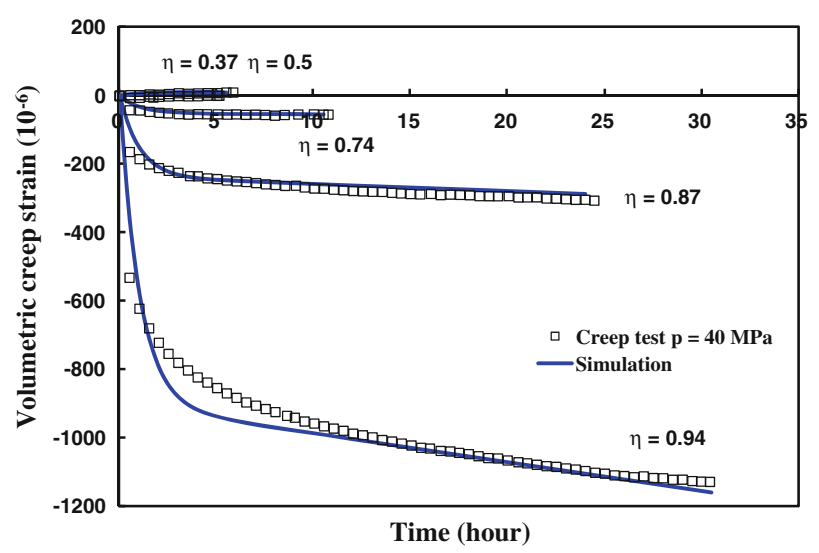

(b) Volumetric creep strain

Fig. 7 Comparison of volumetric creep strain and shear creep strain predicted by the proposed model and data obtained from multistage creep tests under hydrostatic stress of $40 \mathrm{MPa}$ 
strain, the proposed model can simulate the cyclic behavior satisfactorily.

This study also validated the proposed model by comparing with triaxial test results for different stress paths using two other sandstone samples. Weng and Ling (2012) provided additional details regarding these simulations. The comparisons showed that the proposed model satisfactorily captures the instantaneous deformation of sandstone.

\section{Validation of Time-Dependent Behavior}

This section describes simulations of a series of multistage creep tests to further assess the validity of the proposed model regarding time-dependent behavior. First, this section presents a multistage, long-term creep experiment under hydrostatic stress of $40 \mathrm{MPa}$ (Fig. 7). This experiment has five stages of sustained loading with stress ratio $\eta$ ranging from 0.37 to 0.92 . The comparison of the simulated

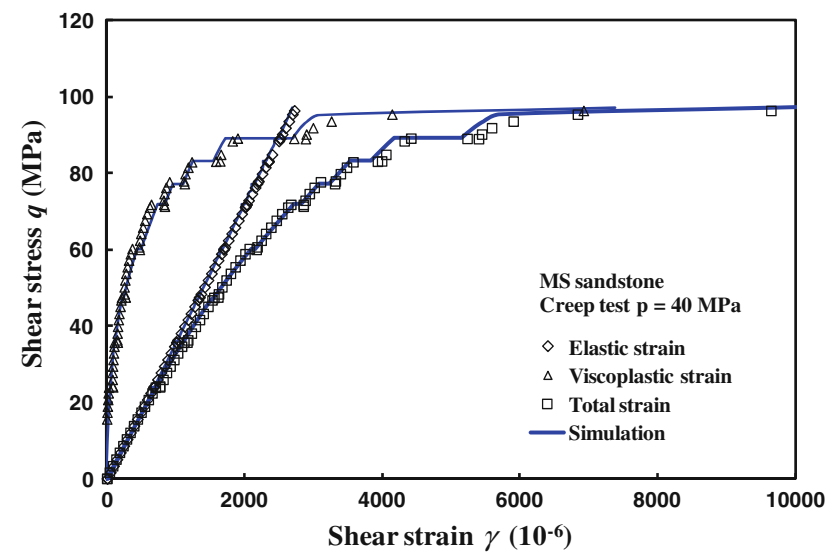

(a) Shear strain

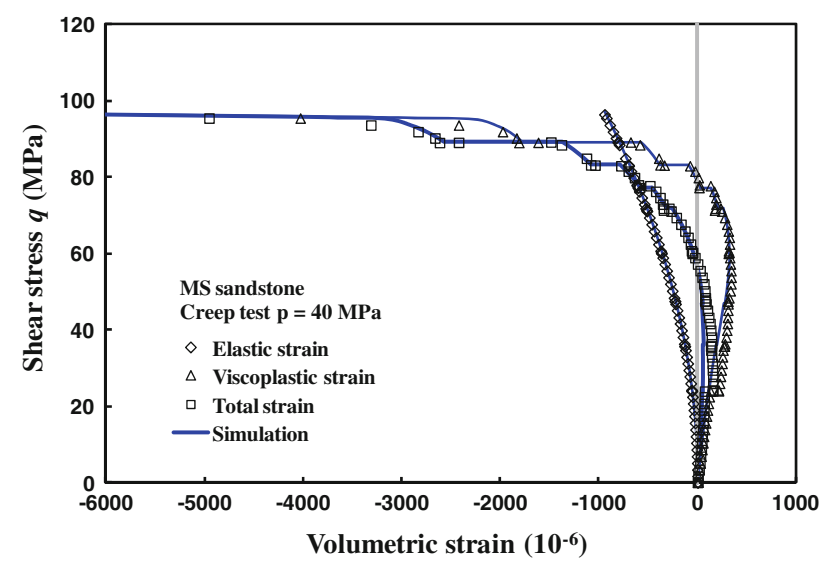

(b) Volumetric strain

Fig. 8 Simulation of the total strain in a multistage creep test, including the decomposed elastic and viscoplastic components induced by the shear stress results with the actual creep behavior of the studied sandstone is as follows:

Figure 7 shows the creep strain predicted by the proposed model and data obtained from the multistage creep test. Table 1 presents the parameter values required for the proposed model.

Regarding the material behavior during shearing, Fig. $7 \mathrm{a}$ and $\mathrm{b}$ show the shear and volumetric strain versus time during the creep stage, respectively. These figures show that a higher stress ratio increases the magnitude of the creep-induced shear strain (Fig. 7a). Figure 7b shows that the simulated volume contracts under lower shear stress and converts to dilative behavior with an increasing shear-stress ratio. The behaviors of the material can be simulated by the proposed constitutive model. Although a minor discrepancy between the simulated and actual behavior occurs in the primary creep deformation, which is attributable to the creep modulus function in Eq. (24) underestimating the creep strain for low stress ratios, the simulated secondary creep deformation is consistent with

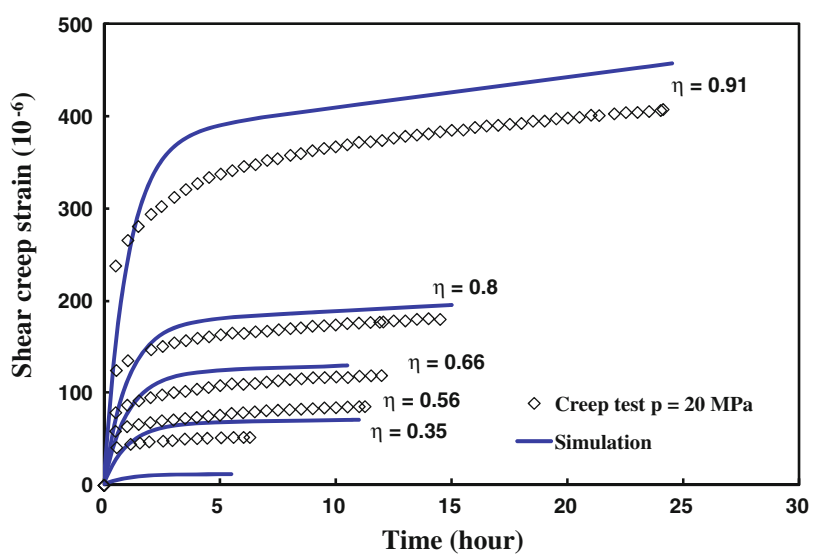

(a) Shear creep strain

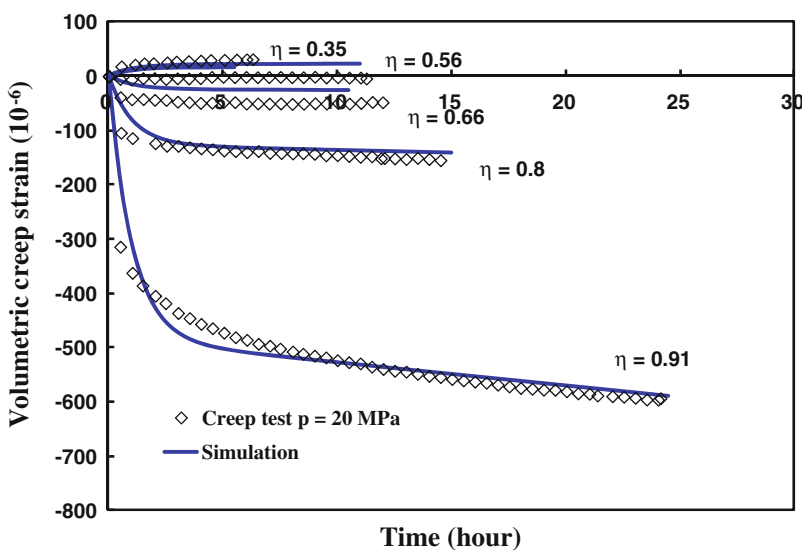

(b) Volumetric creep strain

Fig. 9 Comparison of multistage creep strain predicted by the proposed model and test data under hydrostatic stress of $20 \mathrm{MPa}$ 
the experimental results. Figure 8 shows an additional comparison of the simulated and actual behavior of the total deformation induced by a multistage creep experiment. This figure shows the strain induced by shearing, including the total strain, elastic component, and viscoplastic component. Regarding the elastic component of deformation, the simulations are consistent with the actual results. In addition, viscoplastic volumetric strain is induced by increasing either the shearing or the creep under constant shear loading (Fig. 8b). To increase the shearing, the material first undergoes shear contraction and gradually transitions to shear dilation. Similarly, for creep deformation under constant shear stress, the material transitions from initially contracting to dilating. The proposed constitutive model captures all these material behaviors well.

To further evaluate the predictive capability of the proposed model under different hydrostatic stresses, two additional creep tests at hydrostatic stresses of 20 and $60 \mathrm{MPa}$ were simulated based on the same set of parameters presented in Table 1. Figures 9 and 10 show the

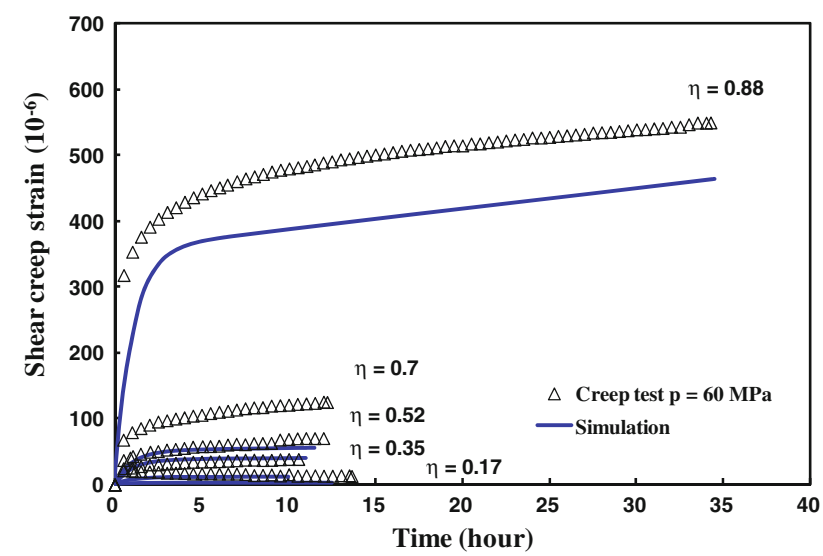

(a) Shear creep strain

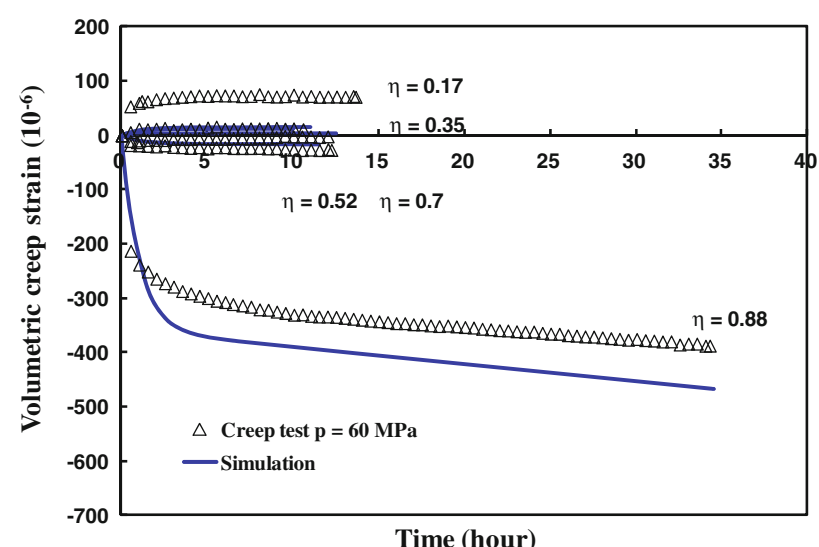

(b) Volumetric creep strain

Fig. 10 Comparison of multistage creep strain predicted by the proposed model and test data under hydrostatic stress of $60 \mathrm{MPa}$ simulated creep strains under different stress ratios $\eta$ from 0.18 to 0.92 . Comparison of the simulated results in Figs. 7, 9, and 10 indicates that the creep strain increases as the shear stress increases, but decreases under higher hydrostatic stress; such comparison also shows that the influence of the shear stress on the creep behavior is more significant than the influence of the hydrostatic stress on the creep behavior. The total deformation in the three multistage creep tests was simulated and is presented in Fig. 11. This figure shows that the proposed model is capable of providing reasonable simulations under various situations.

\section{Wetting Deterioration}

Wetting deterioration is a decrease in material strength and stiffness caused by water penetration. To consider the wetting deterioration of sandstone, this study used other MS sandstone specimens, which are denoted as MS-B, for

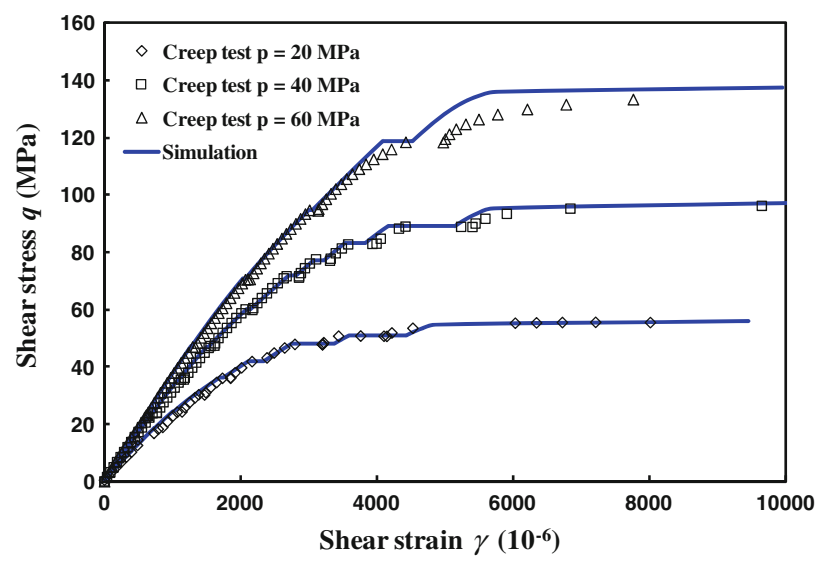

(a) Shear strain

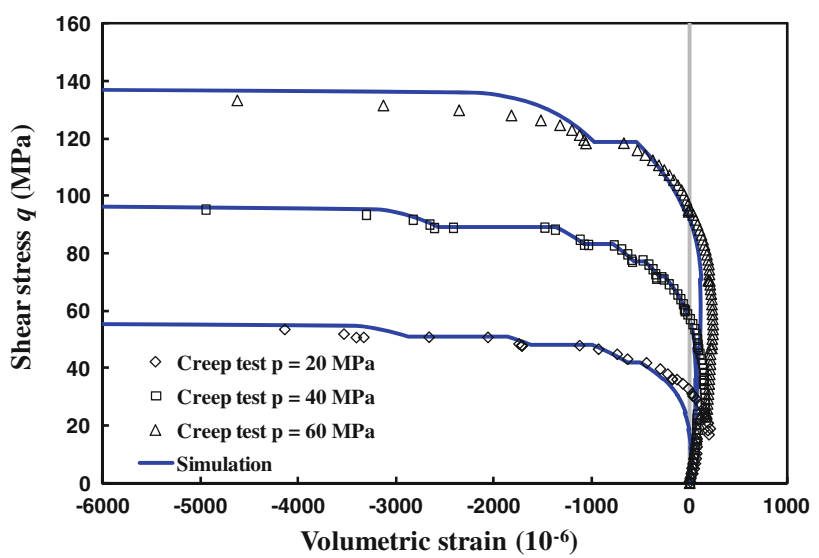

(b) Volumetric strain

Fig. 11 Simulation of strains for multistage creep tests under different hydrostatic pressures 
triaxial tests and multistage creep tests under dry and water-saturated conditions. The MS-B specimens have the following mean physical properties: porosity of $14.0 \%$ and dry density of $2.28 \mathrm{~g} / \mathrm{cm}^{3}$. The average uniaxial

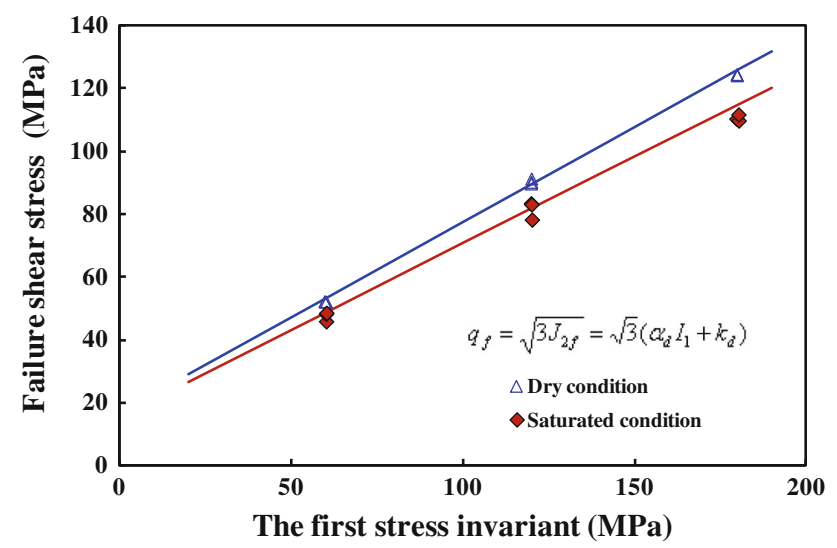

Fig. 12 Failure envelopes of MS-B sandstone under dry and saturated conditions

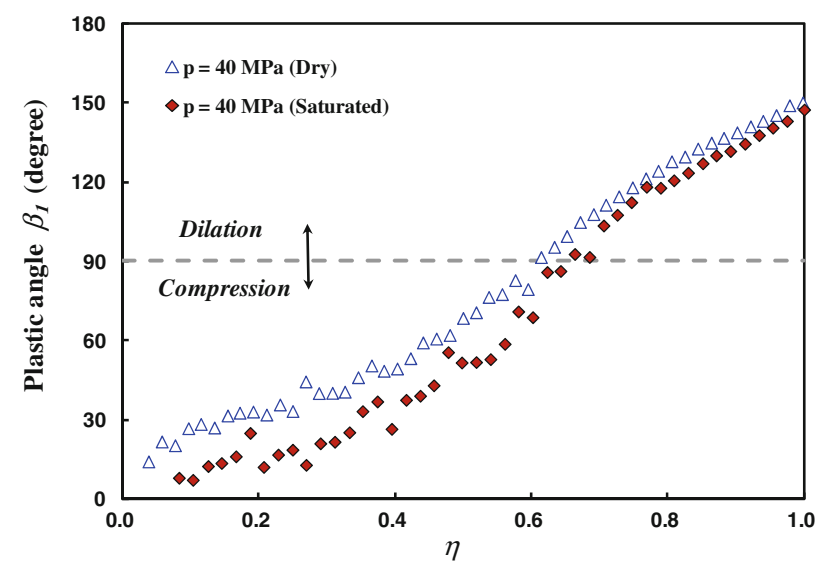

(a) Plastic flow

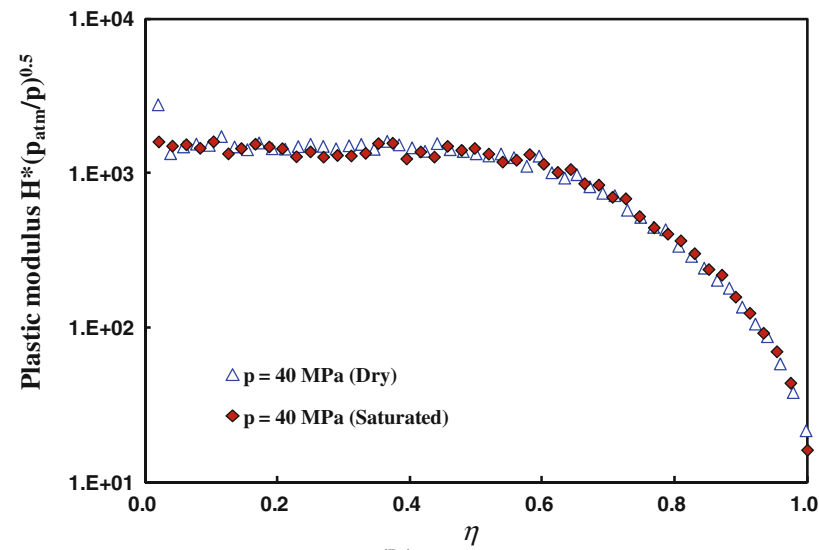

(b) Plastic modulus

Fig. 13 Variations of plastic flow angle $\beta_{1}$ and normalized plastic modulus $H_{\mathrm{L}} \sqrt{p_{\text {atm }} / p^{\prime}}$ under dry and saturated conditions compressive strength is $27.2 \mathrm{MPa}$ in dry conditions and 12.9 $\mathrm{MPa}$ in saturated conditions. Based on petrographic analyses, the percentages of grains, matrices, and voids are $60.0,26.0$, and $14.0 \%$, respectively. The average grain diameter is $\sim 0.34 \mathrm{~mm}$. Mineralogically, MS-B sandstone consists of $88.5 \%$ quartz and $7.2 \%$ rock fragments, and is classified as lithic greywacke.

Figure 12 shows the failure envelopes of sandstone under dry and saturated conditions. The two failure envelopes remain linear under different hydrostatic pressures, and the saturated sandstone has lower shear strength than dry sandstone does. Table 1 presents the corresponding parameters, $\alpha_{\mathrm{d}}$ and $k_{\mathrm{d}}$, both of which are reduced because of wetting deterioration. In addition to the strength, Fig. 13 shows the variations of plastic deformation under dry and saturated conditions. The figure shows that the values of the plastic angle $\beta_{1}$ under dry and saturated conditions exhibit similar tendencies, but the saturated condition has a lower value than the dry condition under the same stress ratio (Fig. 13a), thereby indicating that the dilation threshold in a saturated condition occurs later than that

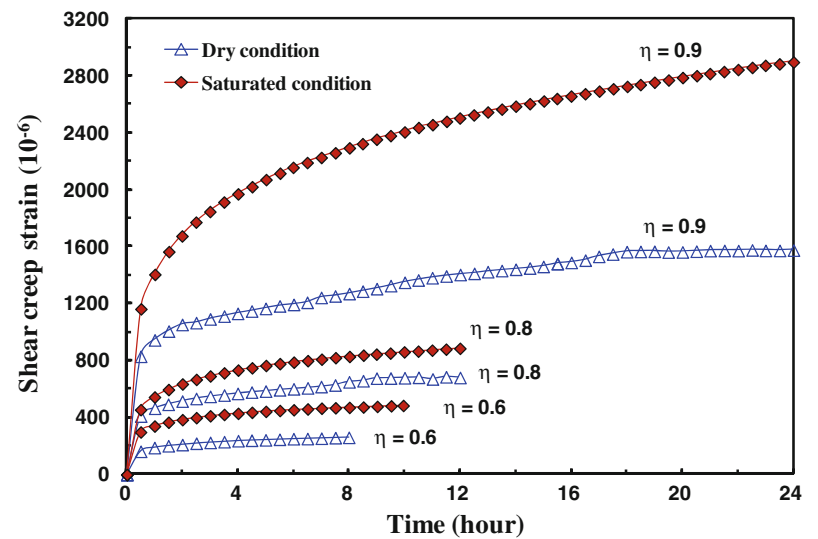

(a) Shear creep strain

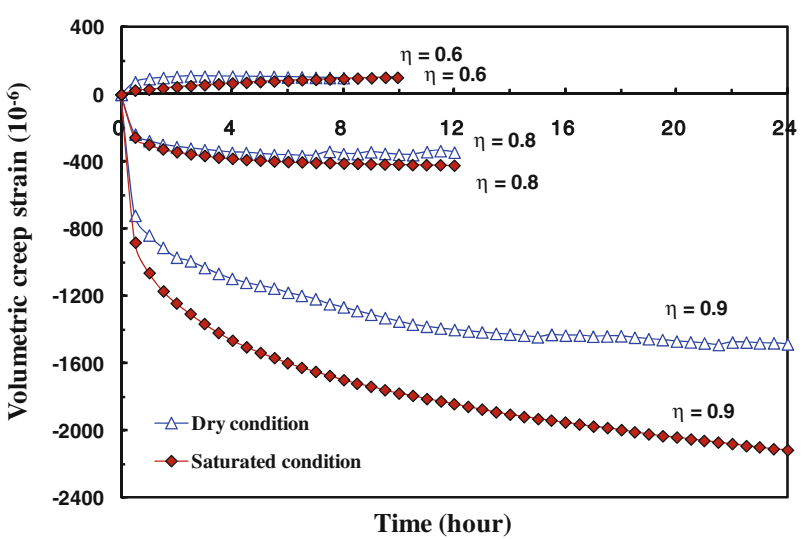

(b) Volumetric creep strain

Fig. 14 Comparison of multistage creep strain under dry and saturated conditions 


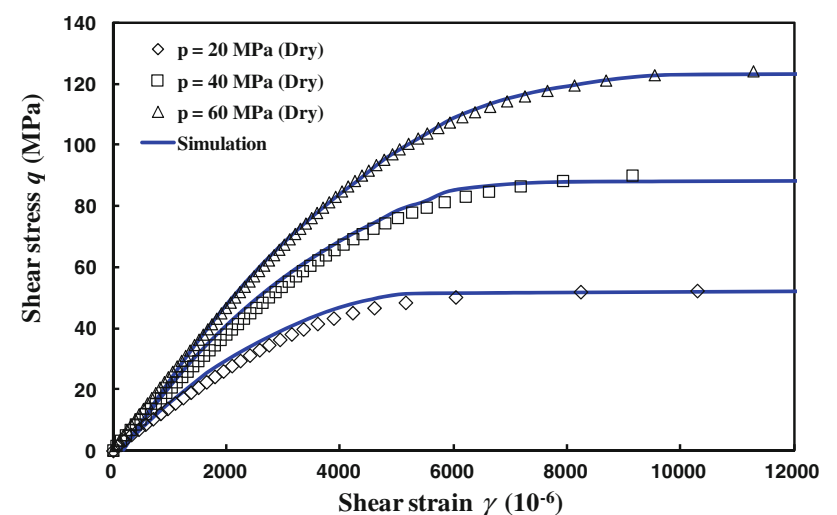

(a) Shear strain

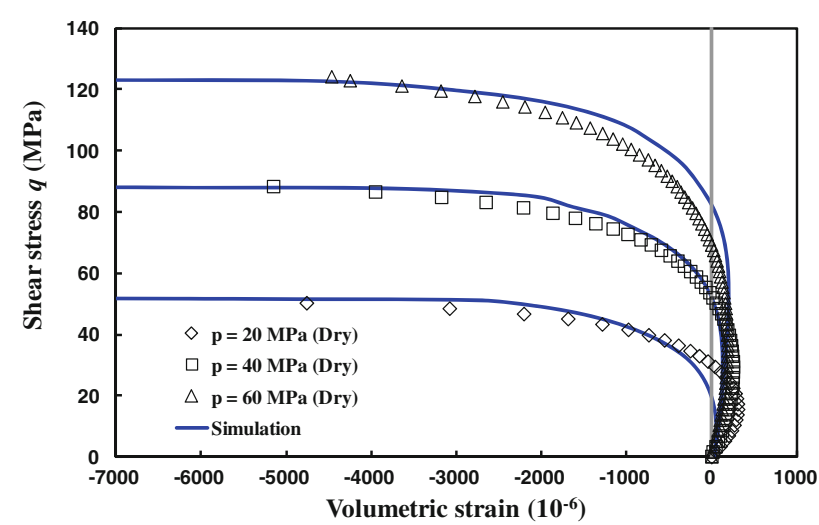

(b) Volumetric strain

Fig. 15 Simulation of stress-strain curves for dry MS-B sandstone under different hydrostatic pressures

under a dry condition. Figure $13 \mathrm{~b}$ shows the variations of the plastic modulus under both conditions. The plastic modulus decreases as the stress ratio increases. When approaching a failure state, the saturated modulus decreases by approximately three orders of magnitude and the dry modulus also exhibits a similar tendency. Figure 14 presents the creep deformation under dry and saturated conditions. Greater creep strains can be induced under saturated conditions, especially when the loading approaches the shear strength. The creep volumetric strain (Fig. 14b) is initially compressive and then becomes dilative at later stages of loading. The amount of creep volumetric strain when approaching the shear strength is considerably greater than that under lower levels of shear stress.

Figures 15 and 16 present simulated results for PS tests under dry and saturated conditions, respectively, to enable an evaluation of the validity of the model. The hydrostatic pressure ranges from 20 to $60 \mathrm{MPa}$. The corresponding parameters of MS-B sandstone are shown in Table 1. The figures show that the proposed model can reasonably

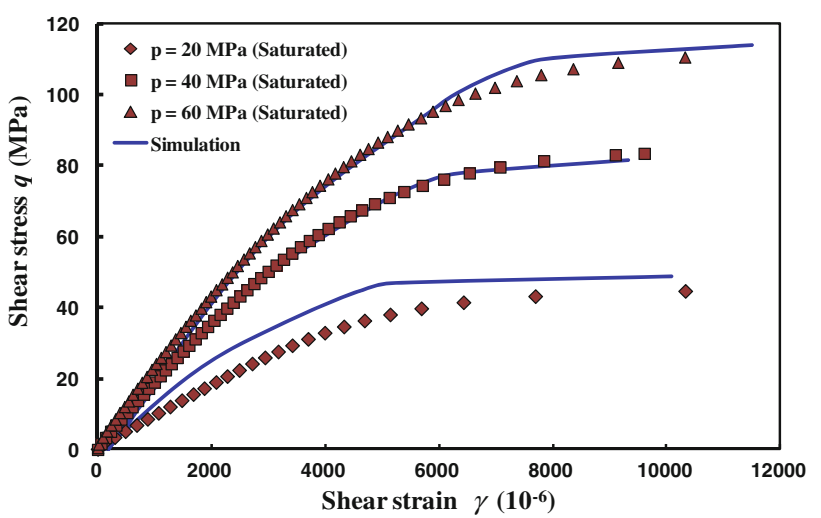

(a) Shear strain

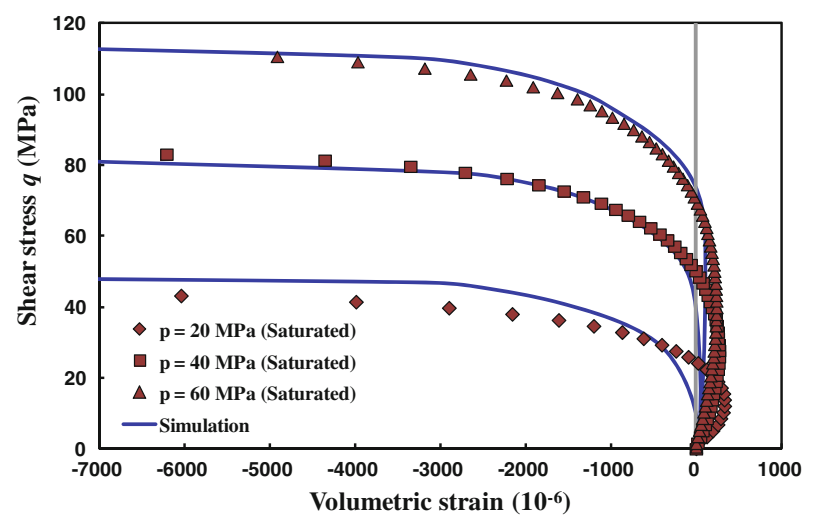

(b) Volumetric strain

Fig. 16 Simulation of stress-strain curves for saturated MS-B sandstone under different hydrostatic pressures

predict the deformation behavior of sandstone caused by wetting deterioration. In addition, Fig. 17 shows the simulated stress-strain curves of the multistage creep tests. This simulation, which is also shown in Fig. 17, is congruent with the experimental data. In summary, the proposed model can predict the behavior of sandstone in dry to saturated conditions.

\section{Conclusions}

This study extends previous research on predicting the time-dependent behavior and wetting deterioration of sandstone and presents a constitutive model based on nonlinear elasticity and generalized plasticity. The proposed model (1) exhibits nonlinear elasticity under hydrostatic and shear loading, (2) follows the associated flow rule for viscoplastic deformation, (3) adopts a creep modulus that varies according to the stress ratio, (4) considers both the primary and secondary creep behavior of rock, and (5) considers the effect of wetting deterioration. 


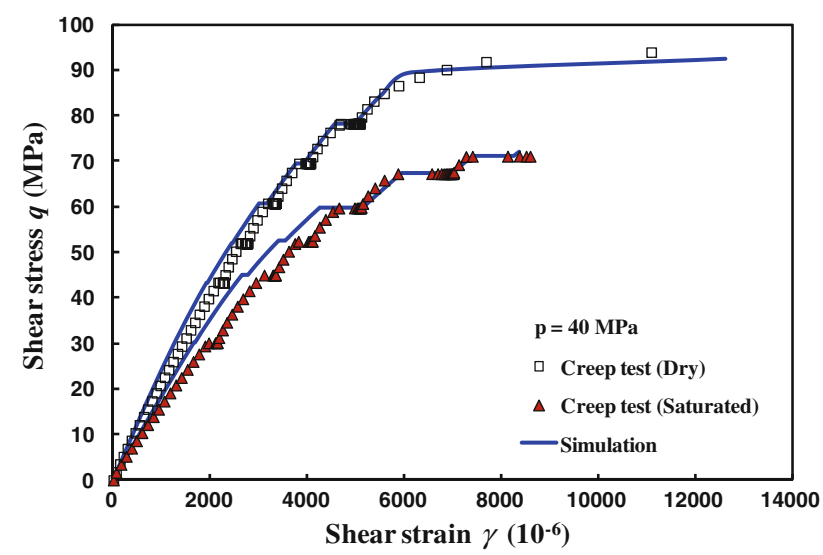

(a) Shear strain

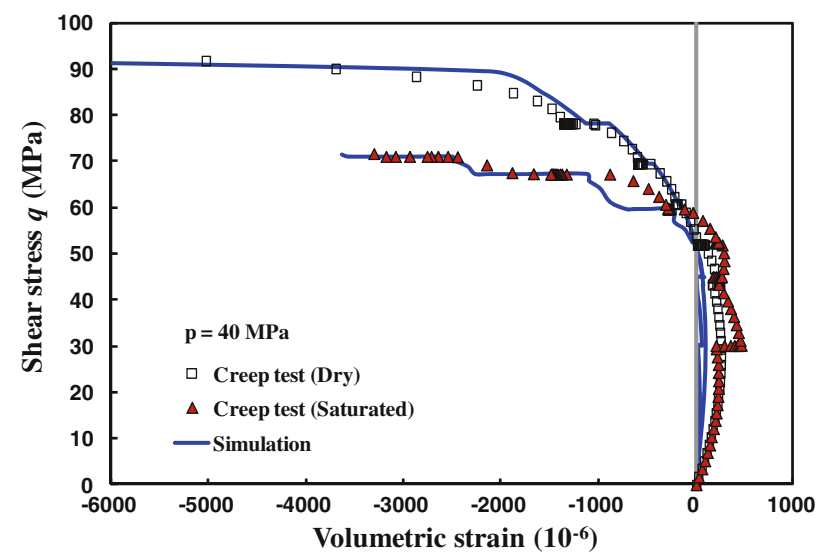

(b) Volumetric strain

Fig. 17 Simulation of strains in the multistage creep test under dry and saturated conditions

This model involves 13 material parameters, comprising 3 for elasticity, 7 for plasticity, and 3 for creep. All parameters can be determined straightforwardly by following the recommended procedures.

For prediction of immediate deformation, this study validates the proposed model by comparison with triaxial test results of MS-A sandstone under various hydrostatic stress and cyclic loading conditions. The proposed model is versatile in simulating the time-dependent behavior of sandstone through a series of multistage creep tests. Furthermore, to consider the effect of wetting deterioration, this study uses MS-B sandstone in triaxial and creep tests under dry and water-saturated conditions. Comparison of the simulated and experimental data shows that the proposed model can predict the behavior of sandstone in dry to saturated conditions. Future studies should extend the presented $\mathrm{q}-\mathrm{p}^{\prime}$ formulation to the multiaxial stress space and incorporate this constitutive model into finite-element software for analytical use in relevant rock engineering applications.
Open Access This article is distributed under the terms of the Creative Commons Attribution License which permits any use, distribution, and reproduction in any medium, provided the original author(s) and the source are credited.

\section{References}

Bolzon G, Schrefler BA, Zienkiewicz OC (1996) Elasto-plastic constitutive laws generalised to partially saturated states. Géotechnique 46(2):279-289

Chan AHC, Zienkiewicz OC, Pastor M (1988) Transformation of incremental plasticity relation from defining space to general Cartesian stress space. Commun Appl Numer Meth 4:577-580

Cristescu ND (1989) Rock rheology. Kluwer Academic, Dordrecht

Dyke CG, Dobereiner L (1991) Evaluating the strength and deformability of sandstones. Q J Eng Geol 24:123-134

Fernandez Merodo JA, Pastor M, Mira P, Tonni L, Herreros MI, Gonzalez E, Tamagnini R (2004) Modelling of diffuse failure mechanisms of catastrophic landslides. Comput Meth Appl Mech Eng 193:2911-2939

Goodman RE (1989) Introduction to rock mechanics. Wiley, New York

Hawkins AB, McConnell BJ (1992) Sensitivity of sandstone strength and deformability to changes in moisture content. Q J Eng Geol $25: 115-130$

Hoek E, Brown ET (1980) Empirical strength criterion for rock masses. J Geotech Eng Div (ASCE) 106(GT9):1013-1035

Houlsby GT, Amorosi A, Rojas E (2005) Elastic moduli of soils dependent on pressure: a hyperelastic formulation. Geotechnique 55(5):383-392

Hoxha D, Giraud A, Homand F (2005) Modelling long-term behaviour of a natural gypsum rock. Mech Mater 37:1223-1241

Jeng FS, Weng WC, Huang TH, Lin ML (2002) Deformational characteristics of weak sandstone and impact to tunnel deformation. Tunn Undergr Space Technol 17:263-264

Jeng FS, Weng WC, Lin ML, Huang TH (2004) Influence of petrographic parameters on geotechnical properties of Tertiary sandstones from Taiwan. Eng Geol 73:71-91

Ling HI, Liu H (2003) Pressure-level dependency and densification behavior of sand through a generalized plasticity model. J Eng Mech 129(8):851-860

Ling HI, Yang S (2006) Unified sand model based on the critical state and generalized plasticity. J Eng Mech 132(12):1380-1391

Manzanal D, Fernández Merodo JA, Pastor M (2006) Generalized plasticity theory revisited: new advances and applications. In: Proceedings of 17th European young geotechnical engineer's conference Zagreb, Zagreb, Croatia, pp 238-246

Manzanal D, Fernández Merodo JA, Pastor M (2011a) Generalized plasticity state parameter-based model for saturated and unsaturated soils. Part 1: saturated state. Int J Numer Anal Meth Geomech 35:1347-1362

Manzanal D, Pastor M, Fernández Merodo JA (2011b) Generalized plasticity state parameter-based model for saturated and unsaturated soils. Part II: unsaturated soil modeling. Int J Numer Anal Meth Geomech 35:1899-1917

Mira P, Tonni L, Pastor M, Fernandez Merodo JA (2009) A generalized midpoint algorithm for the integration of a generalized plasticity model for sands. Int $J$ Numer Meth Eng 77:1201-1223

Pastor M (1991) Modelling of anisotropic sand behaviour. Comput Geotech 11(3):173-208

Pastor M, Zienkiewicz OC (1986) A generalized plasticity, hierarchical model for sand under monotonic and cyclic loading. 2nd International symposium numerical models in geomechanics, Ghent, pp 131-149 
Pastor M, Zienkiewicz OC, Chan AHC (1990) Generalized plasticity and the modelling of soil behaviour. Int $\mathrm{J}$ Numer Anal Meth Geomech 14:151-190

Pastor M, Zienkiewicz OC, Guang-Duo X, Peraire J (1992) Modelling of sand behaviour: cyclic loading, anisotropy and localization. In: Kolymbas Gudehus (ed) Modern approaches to plasticity. Springer, Berlin

Sterpi D, Gioda G (2009) Visco-plastic behaviour around advancing tunnels in squeezing rock. Rock Mech Rock Eng 42:319-339

Tomanovic Z (2006) Rheological model of soft rock creep based on the tests on marl. Mech Time-Depend Mater 10:135-154

Tsai LS, Hsieh YM, Weng MC, Huang TH, Jeng FS (2008) Timedependent deformation behaviors of weak sandstones. Int J Rock Mech Min Sci 45:144-154

Weng MC, Ling HI (2012) Modeling the behavior of sandstone based on generalized plasticity concept. Int J Numer Anal Meth Geomech. doi:10.1002/nag.2127

Weng MC, Jeng FS, Huang TH, Lin ML (2005) Characterizing the deformation behavior of Tertiary sandstones. Int J Rock Mech Min Sci 42:388-401
Weng MC, Jeng FS, Hsieh YM, Huang TH (2008) A simple model for stress-induced anisotropic softening of weak sandstones. Int J Rock Mech Min Sci 45:155-166

Weng MC, Tsai LS, Hsieh YM, Jeng FS (2010a) An associated elastic-viscoplastic constitutive model for sandstone involving shear-induced volumetric deformation. Int J Rock Mech Min Sci 47:1263-1273

Weng MC, Tsai LS, Liao CY, Jeng FS (2010b) Numerical modeling of tunnel excavation in weak sandstone using a time-dependent anisotropic degradation model. Tunn Undergr Space Technol 25:397-406

Xie SY, Shao JF (2006) Elastoplastic deformation of a porous rock and water interaction. Int J Plast 22:2195-2225

Zienkiewicz OC, Mroz Z (1984) Generalized plasticity formulation and applications to geomechanics. Mechanics of engineering materials. Wiley, New York, pp 655-679 